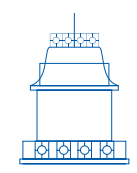

RESEÑ A

\title{
Giraldo, J. (2019). Marx después del marxismo. Medellín: Editorial Universidad de Antioquia
}

\author{
Leandro Sánchez Marín \\ Instituto de Filosofía, Universidad de Antioquia, Medellín, Colombia \\ E-mail: leandro.sanchez@udea.edu.co | ORCID: 0000-0002-6837-1081
}

https://doi.org/10.17533/udea.ef.n62a11

El libro de Jorge Giraldo que es objeto de este comentario presenta una colección de textos publicados en diversos espacios académicos en los últimos diecinueve años. El autor estructura esta reedición de sus trabajos en dos partes bien definidas. La primera se refiere a algunos conceptos de Karl Marx que siempre han estado presentes en el núcleo de los estudios sobre este pensador: política, trabajo, crítica y educación. En la segunda parte, el autor pretende explorar las posibilidades de la relación entre Marx y el liberalismo, más precisamente entre el pensamiento de este último y los de Immanuel Kant y John Rawls. Además de ello, el libro termina con un breve comentario sobre el periplo del autor por algunos lugares vinculados a la biografía de Marx.

La caracterización de Marx como un pensador que no se puede capturar undimensionalmente es un acierto de Giraldo (2019, p. 4). El concepto de unidimensionalidad, que está ostensiblemente vinculado a la obra de Herbert Marcuse (1993), sugiere una forma acabada de los objetos, una forma cerrada que no permite desarrollar más posibilidades que las que estos muestran en un momento preciso de su despliegue. Sorprende por ello que Giraldo entienda que es precisamente Marcuse uno de los autores que considera a Marx de forma unidimensional, argumentando para ello que aquel piensa que todas las categorías del autor de Tréveris tienen un carácter social y económico (p. 6). Lo que se debe entender cuando Marcuse señala esto no es, como cree Giraldo, una visión que rechaza la filosofía y privilegia la economía y la sociología, sino que los conceptos filosóficos de Marx no pueden ser separados de lo 
económico y lo social. Una versión que sí coincide con lo que presenta Giraldo podría ser la de Louis Althusser, quien trató de separar insistentemente la dimensión filosófica y la económica en sus estudios sobre el pensamiento de Marx (Althusser, 2005a, 2005b; Althusser \& Balibar, 2004). Althusser (1974) justificó esta separación apoyándose en lo que llamó un "corte epistemológico" (p. 50) a partir del cual estableció una forma estrecha de interpretación de la obra de Marx con la cual Giraldo no estaría de acuerdo: una forma cerrada, unidimensional. Esta aclaración ayuda a comprender el punto de partida de Giraldo que a mi juicio es interpretativamente muy útil.

Esta forma unidimensional tiene su origen en la extrema politización del pensamiento de Marx que se llevó a cabo por la Unión Soviética. La forma oficial del marxismo era presentada por los regímenes soviéticos como la única válida para interpretar el mundo. Todo lo que fuese contrario a esa oficialidad era considerado como reaccionario o burgués. Por ello gran parte del siglo XX estuvo acompañado por la tergiversación de los conceptos de Marx con la intención de ajustarlos a una forma de vida proletaria y comunista. Los excesos de esta tergiversación derivaron en la construcción de filosofías institucionales, en la postulación de métodos absolutos y en la construcción de políticas que se referían con insistencia a la validez de una única forma de vida como la mejor entre todas las posibilidades del desarrollo humano.

Tom Rockmore, quien escribió un libro con título idéntico al de Giraldo, hace notar claramente las consecuencias de una interpretación unidimensional del pensamiento de Marx: "Durante el período soviético, la ficción de la continuidad absoluta entre Marx, Engels y quien estaba en el poder en ese momento condujo a la monstruosidad autoritaria llamada Marx-Engels-Lenin, Marx-Engels-Lenin-Stalin, más simplemente Marx-Engels-Stalin, Marx-Engels-Lenin-Mao, Marx-Engels-Mao, y así sucesivamente" (Rockmore, 2002, p. 13). La construcción de estos monstruos de múltiples cabezas señala una falsa relación entre Marx y algunos de sus sucesores, pues se toma al primero como un ser idéntico a los segundos. Esta identidad no tiene en cuenta ninguna diferencia, rechaza todo aquello que hace surgir cuestionamientos y genera así una adhesión ideológica que políticamente persigue y acosa toda manifestación contraria.

En el texto de Giraldo se pueden advertir varias sospechas que se unen a versiones como las de Rockmore. Para él es necesario distinguir entre lo que es marxista y lo que es marxiano (Giraldo, 2019, p. 41). Según esto, la letra de Marx sería lo marxiano y las interpretaciones de la letra de Marx serían lo marxista. Sin embargo, la utilización de las supuestas declaraciones de Marx respecto de su desacuerdo con el marxismo (Giraldo, 2019, pp. xi, 4, 41) están, según el criterio de distinción del propio autor, dentro de lo que es marxista, pues ellas no pueden "colegirse rigurosamente" de los textos de Marx (p. 41). Considero que la distinción entre lo que es marxista y lo que es marxiano tiene una validez relativa, pues no se trata de separar definitivamente a Marx del desarrollo del pensamiento marxista y tampoco de adherir a una biblia del marxismo con un dios de varias cabezas. Más bien se trata de considerar los argumentos de la tradición marxista a la luz de lo que ha desarrollado Marx en sus textos y, al mismo tiempo, considerar 
las conexiones entre la tradición del pensamiento filosófico occidental y Marx. De ahí que no resulte tan claro el criterio de distinción de Giraldo, pues varios marxistas son citados por él para la elaboración de sus argumentos en una vía afirmativa. ${ }^{1}$

De esta manera, no considero que una vuelta a Marx pase por la purificación de sus ideas a través de un filtro que condena al marxismo como una simple mala interpretación de las mismas. La exploración del marxismo para una revitalización de Marx debe hacerse más bien a partir de un análisis crítico y una exposición rigurosa de esta tradición de pensamiento. Si de oídas no se puede entender a Marx, pues tampoco de oídas se puede descalificar al marxismo reconociendo sin chistar la validez de unas supuestas palabras de Marx que han llegado hasta nosotros simplemente como un rumor: "Todo lo que sé es que no soy marxista". Si esto es aceptado ciegamente, se hace difícil no aceptar las ideas de segunda mano adjudicadas a Marx a través de los manuales y las citas de Friedrich Engels que pasaron como verdad absoluta del marxismo durante casi todo el siglo XX.

El libro de Giraldo, sobre todo en su primera parte, trata de buscar entre los herederos de Marx a aquellos que son dignos de este título, pero no dice por qué algunos cómo Stalin, por ejemplo, no lo son. Más allá de un rechazo inmediato de autores como este, no nos dice con claridad cuál es la desavenencia fundamental entre ellos y Marx. Esta es una tarea que sí han emprendido algunos autores que él mismo cita, por ejemplo, Alfred Schmidt (2012). En vista de esta insuficiencia en el criterio de distinción que utiliza Giraldo, hay que señalar que una segunda diferenciación entre lo que se llamó marxismo occidental y marxismo soviético o socialismo real, es relevante para la discusión. El marxismo soviético o socialismo real es aquel que manipuló textos de Marx y ocultó algunos de sus manuscritos donde era explícita la crítica a ciertas formas corruptas de comunismo. Ello tuvo como consecuencia, entre otras cosas, el fusilamiento de uno de sus editores, David Riazánov, quién descubrió los llamados Manuscritos de economía y filosofía de Marx y se dispuso a publicarlos, un evento que no fue visto con buenos ojos dentro del régimen de Stalin. Por su parte, el marxismo occidental surgió como respuesta a las formas autoritarias de la Unión Soviética en medio de la Guerra Fría. Varios marxistas rechazaron abiertamente este autoritarismo y el exceso político, social y teórico de sus postulados. Entre ellos estuvo Karel Kosík quien sufrió la arbitraria confiscación de sus manuscritos de trabajo por parte de la policía política checoslovaca (ŠtB) en abril de 1975, además de la prohibición para trabajar como docente universitario y conferencista (Kosík, 1975). De esta segunda distinción podemos derivar la posibilidad de una apertura de Marx hacia relaciones con conceptos como el de libertad, el cual ha sido ampliamente considerado por la tradición liberal.

1 Entre los marxistas con los que Giraldo establece algunos acuerdos interpretativos están: Maurice Merleau-Ponty, Adolfo Sánchez Vázquez, Estanislao Zuleta, Ágnes Heller, Karel Kosík, Alfred Schmidt, Eric Hobsbawm, Terry Eagleton, Gerald Cohen, entre otros. 
Respecto de la relación entre Marx y el liberalismo, Giraldo se propone encontrar algunos vínculos que logren dar cuenta de acuerdos entre este pensador y algunas ideas políticas y filosóficas que no son propiamente marxistas. Aquí el punto de partida que sugiere Giraldo se encuentra bien fundamentado en la idea según la cual la noción de individuo no es un factor extraño al pensamiento de Marx. Para ello se apoya en Estanislao Zuleta y su famoso texto sobre el individualismo en Marx (1987). Asumir a Marx como un provechoso interlocutor del liberalismo es una de las pistas que nos permiten seguir el planteamiento de Giraldo. En primer lugar, el autor considera que el concepto de revolución y su carácter normativo pueden ser analizados teniendo en cuenta las reticencias de Kant con respecto a la Revolución francesa y el optimismo de Marx respecto de las revoluciones obreras de la segunda mitad del siglo XIX. El análisis político de este concepto encuentra en Giraldo una elaboración que vincula a Marx con la idea normativa de una sociedad carente de violencia. Este carácter normativo, a su vez, según Giraldo, construye un puente con Kant en la medida en que el imperativo categórico es retomado radicalmente por Marx (2008):

La crítica de la religión conduce a la doctrina según la cual el hombre es la esencia suprema para el hombre y, por consiguiente, al imperativo categórico de echar por tierra todas las relaciones en las cuales el hombre es un ser humillado, sojuzgado, abandonado y despreciable (p. 103).

Esta idea, como bien reconoce Giraldo, es desarrollada por Oskar Negt en su conferencia de despedida académica en la Universidad de Hannover en 2002, la cual luego se publicaría de forma ampliada bajo el título Kant y Marx. Un diálogo entre épocas. Allí, Negt (2004) sugiere que las contradicciones aparentes entre Kant y Marx pueden encontrar solución en un estudio riguroso del concepto de crítica, pues el primero supo elaborar el concepto revolucionario de crítica epistemológica y el segundo el de crítica radical a la economía política. Hubiese sido provechoso para los intereses de Giraldo un análisis más profundo de este relacionamiento en términos de lo que significa el concepto de revolución en ambos pensadores a la luz de la modernidad, algo respecto de lo cual se pueden encontrar algunas coordenadas en el artículo "Las revoluciones filosóficas: de Kant a Marx" de Adolfo Sánchez Vázquez (1997), un autor que Giraldo también parece conocer. Esto habría encontrado amplia resonancia en la forma en la cual el autor integra a Marx al pensamiento político moderno -del cual había sido apartado por el confinamiento ideológico al cual lo había sometido la oficialidad soviética-, pues, para Giraldo (2019), "Marx es tan moderno como Maquiavelo o Hobbes" (p. 109). ${ }^{2}$

2 En este punto me resulta extraño que Giraldo no se refiera a la tesis de Hannah Arendt —una autora que está muy presente en su trabajo— - según la cual existe un hilo más sólido entre la tradición del pensamiento político occidental y Marx que entre este último y los regímenes totalitarios del siglo XX (Arendt, 2007). 
Para finalizar este comentario, quiero señalar que sobre la misma idea de vinculación entre Marx y el liberalismo se encuentra el trabajo Rainer Forst (2017) quien, a diferencia de Giraldo, opera de manera inversa, es decir, no busca en la tradición liberal los motivos fundamentales de las consideraciones de Marx para luego volverlos a unir con el liberalismo del siglo XX, sino que establece un fortalecimiento de esta tradición en una juntura que primero considera el concepto marxista de alienación y a partir de él reinterpreta los postulados teóricos y prácticos de autores como Kant y Rousseau.

La actualidad de Marx y sus vínculos con el liberalismo encuentra un aporte en el texto de Giraldo, pues invita a discutir respecto de la supuesta obsolescencia de este pensador y la presunta muerte del marxismo tan difundida después de la desaparición del muro de Berlín (Fukuyama, 2015). Además, deja al lector la posibilidad de abrir nuevas indagaciones respecto de categorías que hoy siguen siendo un signo de la sociedad capitalista. Relacionar el trabajo de autores como Giraldo o Forst con lo que se encuentra desarrollado desde hace años por Marx en sus libros, es el síntoma de una renovación de las críticas al capitalismo que son pertinentes en tiempos de crisis como los de hoy.

\section{Referencias}

Althusser, L. (1974). Para una crítica de la práctica teórica. Respuesta a John Lewis (S. Funes, Trad.). Buenos Aires: Siglo XXI Editores.

Althusser, L. (2005a). La filosofía como arma de la revolución (O. del Barco, Trad.). Buenos Aires: Siglo XXI Editores.

Althusser, L. (2005b). La revolución teórica de Marx (M. Harnecker, Trad.). Buenos Aires: Siglo XXI Editores.

Althusser, L., \& Balibar, É. (2004). Para leer El Capital (M. Harnecker, Trad.). Buenos Aires: Siglo XXI Editores.

Arendt, H. (2007). Karl Marx y la tradición del pensamiento político occidental (M. López \& A. Serrano, Trads.). Madrid: Ediciones Encuentro.

Forst, R. (2017). Noumenal Alienation. Rousseau, Kant and Marx on the Dialectics of SelfDetermination. Kantian Review, 22, 523-551. https://doi.org/10.1017/S1369415417000267 Fukuyama, F. (2015). ¿El fin de la historia? y otros ensayos (J. García-Morán, Trad.). Madrid: Alianza Editores.

Giraldo, J. (2019). Marx después del marxismo. Medellín: Editorial Universidad de Antioquia.

Kosík, K. (1975). The Kosík-Sartre Exchange. Telos, 25, 193-195. https://doi.org/10.3817/0975025193

Marcuse, H. (1993). El hombre unidimensional. Ensayo sobre la ideología de la sociedad industrial avanzada (A. Elorza, Trad.). Bogotá: Editorial Planeta de Agostini.

Marx, K. (2008). Escritos de juventud sobre el Derecho. Textos 1837-1847 (R. Jaramillo, Trad.). Madrid: Anthropos Editorial. http://www.digitaliapublishing.com/a/15682 
Rockmore, T. (2002). Marx after Marxism. The philosophy of Karl Marx. Blackwell Publishers. Sánchez Vázquez, A. (1997). Filosofía y circunstancias. Madrid: Anthropos Editorial.

Schmidt, A. (2012). El concepto de naturaleza en Marx (E. Prieto, Trad.). Buenos Aires: Siglo XXI Editores.

Zuleta, E. (1987). Ensayos sobre Marx. Medellín: Editorial Percepción. 